\author{
Professor, Iuliana CETINĂ, PhD \\ The Bucharest University of Economic Studies \\ Professor, Luigi DUMITRESCU, PhD \\ "Lucian Blaga" University of Sibiu, Faculty of Economics \\ Assistant Professor, Mircea FUCIU, PhD \\ "Lucian Blaga" University of Sibiu \\ Professor, Gheorghe ORZAN, PhD \\ Cristina STOICESCU, PhD Candidate \\ The Bucharest University of Economic Studies
}

\title{
MODELLING THE INFLUENCES OF ONLINE SOCIAL NETWORKS ON CONSUMERS' BUYING BEHAVIOUR
}

\begin{abstract}
The emergence of the online social networks (OSN) has created for companies and marketing specialists a brand new method of reaching and communicating with their target groups. This paper aims to present the results of a quantitative marketing research (part of a larger qualitative and quantitative marketing research) which was designed in order to identify if and how the online social networks influence the consumers' buying behaviour. We presented a short literature review regarding the concepts of online social networks, consumer behaviour, economic and marketing models as well as several marketing models linked to the usage of information technology by the consumers. The second part of our paper presents the research methodology, the proposed conceptual model of online social networks influences on the purchasing behaviour and the validation process. We have shown, following the statistical analysis, that the online social networks influence in certain aspects the buying behaviour of the consumers. We concluded by underlining certain theoretical and managerial implications, as well as by drawing some conclusions and pointing out several research limits.
\end{abstract}

Keywords: online social networking, marketing research, marketing model, impact, factor analysis.

\section{JEL Classification: M30}

\section{Introduction}

In the context of the Internet development as a medium of communication globally, especially in the second half of the 90s of last century, and against the background of a large number of companies and organizations that operate through the Internet-based or online, more than 10 years ago has appeared online in a new platform

DOI: $10.24818 / 18423264 / 52.2 .18 .01$ 
for communication and interaction: online social networks. Online social networks have become in the last decade one of the most used forms of online communication.

Considering this, especially due to the desire to understand the buying behaviour of individuals in the online environment, we believe it is extremely important to understand how these online platforms are used by individuals or companies and what effects online social networks have on the purchasing behaviour of individuals. Starting from the premise that online social networks have an important impact on the purchasing behaviour and this area is not sufficiently well covered in the specialised literature, we considered it a very important reason to address this research issue.

Our paper represents an important part of a quantitative marketing research undertaken in 2014 and 2015 by the authors and it presents, on one side, a brief literature review regarding the concept of social networks, online social networking sites, as well as some aspects related to consumer behaviour and consumer modelling in the context of using information technology, and on the other side we are presenting the research methodology and the validation of a marketing model entitled Model of online social networks' influences on the purchasing behaviour (I-OSN-CC). The paper ends with several conclusions, managerial implications and acknowledgments and limits of our research.

\section{Literature review}

The emergence and development of ICT tools led in parallel to a strong business development. In recent decades, this development has had an impact on how to do business and to address consumers. The Internet has enabled consumers everywhere to get information quickly, at any time and from almost any corner of the world. One of the tools that are used both by individuals and by companies or marketers is represented by online social networks.

It is necessary to differentiate between two types of social networks. On one side there are the social networks that treat human relationships outside the virtual environment, and on the other side there are the social networks which raise the question of human or organizational relations, conducted by supporting the online information environment.

Firstly, the first variant should be emphasized, and according to Oxford Online Dictionary social networks ,are all the social network interaction as well as the personal relationships of the individual".

Traditional social relations are studied for over half a century, these studies currently directing on interpersonal relationships in small group, due to the inability to obtain large amounts of data. According to the authors Acatrinei and Nistor (2012) social networks are „dynamic social systems that favour the development of relations between individuals through a content created and shared by them". Starting from these concepts and from the new developments in information and communication technology, a new trend develops: that of social dialogue media (social media) using the online medium. Social networking sites 
Modelling the Influences of Online Social Networks on Consumers' Buying Behaviour

have gained an unprecedented popularity in recent years, currently hundreds of millions of individuals or organizations being users of such systems.

Online social networks are currently considered as the sites most popular on the Internet, aimed mainly at distributing, in a unique way, general information or particular information on products or services.

Other similar definitions presented by Preece and Maloney Krishmar (2005) present online social networks as ,individuals who get together for a reason and that are guided by specific policies ... using a software." According to several authors (Boyd and Ellison, 2007), online social networks are „Internet-based services that allow individuals: to create their public or semi-public profile under a prearranged system; to create a list of other users with whom they are related; and to view and cross the list of connections with all persons in the system."

Analysing the definitions of social networking sites presented above and by other authors (Cain, 2008; Kwon and Wen, 2010; Heidemann et al., 2012) we can notice a series of characteristics common to all these concepts: (1) the existence of an Internet connection; (2) the development or use of a default online platform; (3) the ability to communicate quickly with people you know and not only or people with common interests; (4) the ability to post personal information regarding the user or information regarding the organizations; the ability to create specialized groups in which individuals / organizations interact in precise, separate areas, which are of interest to people interested / involved, etc.

The second part of the literature review for this paper covers aspects related to the consumer, the concept of economic modelling as well as several examples of marketing consumer models connected to the usage of information technologies.

The process of studying the consumer behaviour and the purchasing process have emerged as a distinct field of knowledge the mid to late '50s and early' 60s of the last century. The American Marketing Association offered two definitions of consumer behaviour as: (1) „The dynamic interaction of effects, cognitive issues, behaviour and the environment through which people make exchanges in their lives; (2) Consumer behaviour or the behaviour of the decision maker in the market for products and services. It is often used to describe the interdisciplinary scientific study that seeks to understand and describe such behaviour."

Romanian specialists in marketing have defined purchasing behaviour as ,all acts of decision made at the level of individual or group, directly linked to obtaining and using goods and services in order to meet current and future needs, including decision-making processes that precede and determine these acts" (Cătoiu and Teodorescu, 2004).

Michael Solomon, in his paper Consumer Behaviour - a European perspective (Solomon et al., 2010, p. 6), continues the process of defining this concept as: „the study of the processes involved in the work of individuals or groups of individuals who choose, purchase, use or dispose of products, services or ideas that lead to consumer needs or desires".

DOI: $10.24818 / 18423264 / 52.2 .18 .01$ 
Related to the concept of economic models and marketing models, we must start by stating that the process of building marketing models was started in the second part of the '50s. In the last two decades, the marketing modelling process has undergone major changes, especially because of the extremely important use of information in marketing activity (Leeflang et al 2000).

According to Cassady (in Cătoiu et al., 2009, p. 611), the economic model is defined as ,a simplified replica of existing systems or segments built to discover and demonstrate the possibility of obtaining economic results in certain given conditions." Professor Cătoiu (Cătoiu et al., 2009) defines the model as ,,a representation of some or all properties of a larger system and if the system is a medium totally surrounding the issue, the model is a description of the system's aspects that are essential for analysis."

Iacobucci $(2013$, p. 2) defines the economic models ,a much simpler representation of the environment (world), being built to have a much better understanding of it and to develop predictions about the environment."

The modelling process involves creating a logical and abstract format, which allows the organization of the analyst's thinking process, and beyond. Economical modelling is a complex process, according to Ruxanda and Muraru (2010) stat that "when modelling economic variables, it frequently happens that the variables intended to be explicative and, therefore, exogenous variables in the regression model have a simultaneous behaviour with the endogenous variables, and, consequently, lose their exogeneity characteristics", a fact that we have to take into account and be certain of what are the main elements that we add to the modelling process and to understand it.

We also wish to emphasize and at the same time to highlight the concept of marketing model which in recent decades has become a central element in understanding the buying behaviour of individuals and / or organizations. Marketing model is (Cătoiu et al., 2009, p. 612) ,a set of variables and relationships between them, designed to represent a real system or process of marketing.

After analysing the definition above, to which we subscribe, as well as those presented by other authors (Eliashberg and Lilien, 1993, Lilien and Roberts, 1993, Lilien and Rangaswamy, 2008) one can see a number of specific characteristics of economic models, in general and models of marketing, in particular: (1) representation of a system / environment; (2) representation of events, objects, processes etc. (3) identification and expression of the relationships that exist between the components of the model.

In order to understand how the online social networks influence the consumer behaviour and its buying behaviour we consider it necessary to underline several important marketing models that present the usage of the information technology in relation to the consumer.

The Theory of Reasoned Action (TRA), developed in 1975 by Martin Fishbein and Icek Ajzen was a pioneer in developing a conceptual framework to predict, explain and change individuals' social behaviour (Ajzen, 2012, p.11). The authors of this model have shown that basic beliefs, both the normative and behavioural, the intentions and the behaviour of individuals can be measured and it is extremely important to have a high degree of correlation between attitudes, 
Modelling the Influences of Online Social Networks on Consumers' Buying Behaviour

norms, perceived control, intention and behaviour within action, target, context of the action and time. Any changes affecting these factors lead to different behaviours.

The theory of planned behaviour (TPB) is a theory that was developed by the famous psychologist Icek Ajzen (Ajzen, 1985) as a continuation of the Theory of reasoned action and posits the idea that ,the actions of individuals are determined by their traits and attitudes. The features are defined as a characteristic of an individual who exercises a permanent influence on a wide range of relevant answers for that feature."

Technology Acceptance Model (TAM) developed by Davis (Davis, 1989), based on the theory of reasoned action and the theory of planned behaviour.The main goal of TAM is to provide a clear explanation on the main determinants of acceptance of computers in general which to be able to explain users' behaviour in terms of technologies or types of individuals. Flow theory was first postulated by psychologist Csikszentmihalyi in 1975. According to him, the flow is "the holistic sensation that individuals feel when they act with total involvement".

According to this theory, three important dimensions operate in the flow: concentration/focus, interest, pleasure. Meanwhile, in the use of technology and online consumer behaviour, the theory of flow knows four main dimensions: concentration/focus, pleasure, time distortion, telepresence.

At the same time, we consider that the online social networks influence the consumer from several perspectives:(1) the emergence and development of consumers' needs and desires; (2) online social platforms are also used by consumers to search for information about products or services they need or want (Fuciu and Dumitrescu, 2014); (3) through opinions, recommendations, reviews, video content posted on social networking platforms have a positive effect on the evaluation of alternatives regarding products and/or services, but also on the evaluation's results, whether it is purchase or not purchase or postponement (Alsubagh, 2015); moreover, using the same opinions, recommendations, comments etc. consumers express satisfaction or dissatisfaction with the products or services purchased both online and offline. These assumptions regarding the theoretical influence of online social networks are based on several researches undertaken by the authors in order to understand how these platforms are influencing the consumers' behaviour.

\section{Research methodology}

The marketing research aimed at identifying the influences that online social networks have on the purchasing behaviour of their users. Consequently, 19 specific marketing objectives were established (based on the literature review and the results of previous research).

The sources of information needed were established and the observation unit considered in this research is the online social network users and is the same 
with the research unit, i.e. the individual. The instrument used for data collection was a questionnaire (distributed online) consisting of 28 questions divided into three sections that were arranged according to the principle of the funnel (from general to particular).

Sampling was improbable by the "snowball" method and "operating principle of this method involves the identification, by the researcher, based on specific reasons, of a number of respondents to be investigated and which in turn will recommend to the researcher other respondents to be covered by the marketing research" (Cătoiu et.al., 2009, p.525). A probability coefficient of $95 \%$ was used, taken from statistical tables value of $\mathrm{t}=1.96$, the calculated margin of error being \pm $5.8 \%$. The identification of a characteristic that would differentiate respondents led to determining the value of $p=0.5$, automatically resulting the value of $q=0.5$.

Following the questionnaire, the collection of 788 questionnaires from respondents resulted. They were checked in the sense of being completed correctly and completely, and after this process a number of 294 valid questionnaires resulted (representing a valid response rate of $37.30 \%$ ). Causes of elimination of almost 500 questionnaires was that they were either not fully completed or surveys were started (the link received was accessed) but the initial explanation of the questionnaire was not completed. The marketing research results were divided into two categories: the descriptive data analysis, creating a profile of online social networks user (Fuciu, 2015; Dumitrescu et al., 2015) and the proposition of the marketing model and its validation. The last two elements (the proposed and validated model are presented in the next section of this paper).

\section{Research Analysis and Discussion}

The model was created from the ideas and design of other older marketing models: The Theory of Reasoned Action - TRA (Ajzen, 2012, p. 11); The Theory of Planned Behaviour - TPB (Ajzen, 1985); Technology Acceptance Model 1 and 2 - TAM 1 and 2 (Venkatesh and Davis, 2000); the technology acceptance and flow theory in online consumer behaviour (Koufaris, 2002, p. 213).

These models and others (Di Pietro and Pantano, 2012) together with the buying process, have led to the proposal of a marketing model by the name of Model of online social networks' influences on the purchasing behaviour (I-OSN-CC). The conceptual model proposed has two important components that should be mentioned: (1) purchasing behaviour - emergence of the need; looking for information; evaluation of alternatives; decision (purchasing decision, nonpurchasing decision, and deferred purchase); and post purchase evaluation. (2) the facts of influence acting within online social networks - commercials / advertising; timeliness of the information; positive and negative experiences (related to products / services) expressed by these platforms; views/ opinions expressed on these platforms; recommendations on products or services etc.

The proposed conceptual model involves analysing the influence of a number of observable variables on the latent variables, which in turn have an 
Modelling the Influences of Online Social Networks on Consumers' Buying Behaviour

influence effect on the purchasing behaviour of the individual. The testing and validation activity of the conceptual model proposed is a complex activity that involves going through several important stages in the process of marketing modelling:

(a) Determining the accuracy of measurements through Cronbach's Alpha coefficient;

To achieve a clear analysis of the data, it was considered necessary to carefully consider the measurement process and its accuracy and the internal consistency of latent variables in the research. Thus, the SPSS v.20 statistical analysis software was used to calculate Cronbach's alpha coefficient. This coefficient values between 0 and 1 (Cătoiu et. al., 2009, p. 182), and to ensure that the items analyzed significantly influence the latent variables, Cronbach's alpha coefficient should be at least 0.70 .

Table 1. Cronbach's Alpha coefficient Reliability Statistics

\begin{tabular}{|r|r|r|}
\hline $\begin{array}{c}\text { Cronbach's } \\
\text { Alpha }\end{array}$ & $\begin{array}{c}\text { Cronbach's Alpha Based on } \\
\text { Standardized Items }\end{array}$ & N of Items \\
\hline .862 & .866 & 15 \\
\hline
\end{tabular}

(Source: authors' computation)

The calculated Cronbach's Alpha coefficient, has a value of 0.866 , which means that measurements in the study are accurate (the minimum accepted value is 0.70). Also, the values of observed variables were calculated with Cronbach's Alpha coefficient, which took values between 0.851 and 0.861 , which represents that the calculated variables significantly influence the latent variables and exceed the significance threshold of 0.70.The calculated coefficients demonstrate the accuracy of the measurement, and the internal consistency of latent variables in the research.

(b) Correlation analysis between the variables investigated and the purchasing decision making stages;

Before starting on the correlation analysis, we have undertaken a homogeneity test for the variables taken into analysis. The results are shown in table 2 and they point out that the variation coefficient takes values from 0.162 (16.23\%) for promotion activities and $0.372(37.22 \%)$ for the negative experiences expressed by strangers. According to the specialized theory, the data series is regarded as homogeneous if the value does not exceed $35 \%$. We can see that there is a slight increase (over 35\%) in 2 cases. 
Iuliana Cetina, Luigi Dumitrescu, Mircea Fuciu, Gheorghe Orzan, Cristina Stoicescu

Table 2. Variation coefficient and data homogeneity

\begin{tabular}{|l|c|c|c|}
\hline \multicolumn{1}{|c|}{ Variables } & Average & $\begin{array}{c}\text { Standard } \\
\text { deviation }\end{array}$ & $\begin{array}{c}\text { Variation } \\
\text { Coefficient }\end{array}$ \\
\hline Companies' pages & 3.146 & 1.003 & 0.319 \\
\hline Products' / services' pages & 3.435 & 0.913 & 0.266 \\
\hline Promotion activities & 4.133 & 0.671 & 0.162 \\
\hline Accuracy of available information & 3.694 & 0.891 & 0.241 \\
\hline General source of information & 3.619 & 0.800 & 0.221 \\
\hline Information sources for product/services & 3.595 & 0.876 & 0.244 \\
\hline Positive experiences friends / acquaintances & 3.963 & 0.802 & 0.202 \\
\hline Positive experiences unknown individuals & 2.929 & 1.111 & 0.379 \\
\hline Negative experiences friends / acquaintances & 4.024 & 0.824 & 0.205 \\
\hline Negative experiences unknown individuals & 2.915 & 1.085 & 0.372 \\
\hline General opinions & 3.150 & 0.893 & 0.283 \\
\hline Opinions about products or services & 3.728 & 0.776 & 0.208 \\
\hline Criticism about products or services & 3.204 & 1.064 & 0.332 \\
\hline Recommending products / services in general & 3.282 & 0.991 & 0.302 \\
\hline Recommending products / services by friends & 3.041 & 1.011 & 0.332 \\
\hline
\end{tabular}

(Source: authors' computation)

After this analysis we analysed the correlations between observable variables and identified latent variables. With this analysis we wanted to highlight, through the Pearson correlation coefficient, a link between the variables under investigation, the level of intensity of the relationship and the meaning and form of the relation. Therefore, the Pearson correlation coefficient was calculated, taking values between 0.499 - Negative experiences expressed by friends / acquaintances and 0.678 - General sources of information. It is known that Pearson correlation coefficient has values between $[-1 ;+1]$, and the results show that the correlation between observed and latent variables is positive, of medium intensity. The entirety of the Pearson correlation is shown in figure 1, which presents a graphic representation of our model

\section{(c) Exploratory factor analysis.}

Factorial analysis is a category of multivariate statistical methods whose purpose is the research of ties and interdependence between several variables by which to characterize a particular phenomenon, by reducing (condensation) the data volume contained in the initial variables and establishing a smaller set of dimensions (factors), aiming at a minimal loss of information (Cătoiu et. al., 2009, p. 557). 
Modelling the Influences of Online Social Networks on Consumers' Buying Behaviour

The first step in the factorial data analysis is the application of KaiserMeyer-Olkin test to learn the extent of adequacy of the chosen sample. KMO test is a method that can be used both for single and multiple variables and it represents the squared sums of correlation coefficients between variables and partial correlation coefficients' sum. KMO takes values between 0 and 1 .

The second test required to guarantee a successful factorial analysis is given by the Bartlett sphericity test testing the extent to which the matrix of correlations differ from an identity matrix and the degree of common variation of the analysed variables. Using the IBM SPSS v.20, the two tests were calculated, and table 3 gives the KMO and Bartlett test results.

Table 3. Values of the Kaiser-Meyer-Olkin and Bartlett tests

\begin{tabular}{|c|c|c|}
\hline \multicolumn{2}{|c|}{ Kaiser-Meyer-Olkin Measure of Sampling Adequacy } & 0.774 \\
\hline \multirow[t]{3}{*}{ Bartlett's Test of Sphericity } & Calculated value $\chi^{2}$ & 2329.004 \\
\hline & Degrees of freedom (df) & 105 \\
\hline & $\begin{array}{l}\text { Statistical significance } \\
\text { (Sig.) }\end{array}$ & 0.000 \\
\hline
\end{tabular}

(Source: authors' computation)

The value of $\mathrm{KMO}$ is 0.774 , which means that the correlations model is compact and factorial analysis offers distinct factors that help to understand the phenomenon studied. At the same time, the level of statistical significance Sig. calculated is lower than 0.05 , and the Bartlett test value (calculated value $\chi^{2}$ ) is: 2329.004 with 105 degrees of freedom.

Factorial analysis showed factors extracted from the application of principal components method (table 4). Thus, it can be seen that the first 5 components extracted sum up $74.046 \%$ of the variance of all extracted components (Extraction Sums of Squared loadings) and initial components (Initial Eigenvalues).

Based on these data we can conclude that of all the 15 initial variables taken into consideration, through which the influence of social online networks on the purchasing behaviour was analysed, can be grouped in five factors / items without causing a significant loss of data.

Table 4. Total variance of factors explained

\begin{tabular}{|c|c|c|c|c|c|c|c|c|c|}
\hline \multirow{2}{*}{$\begin{array}{c}\text { Com } \\
\text { po } \\
\text { nent }\end{array}$} & \multicolumn{3}{|c|}{ Initial Eigenvalues } & \multicolumn{3}{c|}{$\begin{array}{c}\text { Extraction Sums of Squared } \\
\text { Loadings }\end{array}$} & \multicolumn{3}{c|}{$\begin{array}{c}\text { Rotation Sums of Squared } \\
\text { Loadings }\end{array}$} \\
\cline { 2 - 10 } & Total & $\begin{array}{c}\text { \% of } \\
\text { Variance }\end{array}$ & $\begin{array}{c}\text { Cumul } \\
\text { ative } \\
\text { \% }\end{array}$ & Total & $\begin{array}{c}\text { \% of } \\
\text { Variance }\end{array}$ & $\begin{array}{c}\text { Cumulat } \\
\text { ive \% }\end{array}$ & Total & $\begin{array}{c}\text { \% of } \\
\text { Variance }\end{array}$ & $\begin{array}{c}\text { Cumul } \\
\text { ative } \\
\text { \% }\end{array}$ \\
\hline 1 & 5.306 & 35.374 & 35.374 & 5.306 & 35.374 & 35.374 & 2.552 & 17.016 & 17.016 \\
2 & 1.926 & 12.837 & 48.211 & 1.926 & 12.837 & 48.211 & 2.221 & 14.808 & 31.823 \\
3 & 1.524 & 10.158 & 58.369 & 1.524 & 10.158 & 58.369 & 2.204 & 14.695 & 46.518
\end{tabular}


Iuliana Cetina, Luigi Dumitrescu, Mircea Fuciu, Gheorghe Orzan, Cristina Stoicescu

\begin{tabular}{|l|r|r|r|r|r|r|r|r|r|}
4 & 1.202 & 8.013 & 66.382 & 1.202 & 8.013 & 66.382 & 2.184 & 14.562 & 61.080 \\
5 & 1.150 & 7.664 & 74.046 & 1.150 & 7.664 & 74.046 & 1.945 & 12.966 & 74.046 \\
6 & .847 & 5.644 & 79.691 & & & & & & \\
7 & .615 & 4.099 & 83.790 & & & & & & \\
8 & .614 & 4.096 & 87.886 & & & & & & \\
9 & .484 & 3.227 & 91.112 & & & & & & \\
10 & .338 & 2.254 & 93.366 & & & & & & \\
11 & .265 & 1.764 & 95.130 & & & & & & \\
12 & .232 & 1.546 & 96.676 & & & & & & \\
13 & .208 & 1.389 & 98.065 & & & & & & \\
14 & .159 & 1.059 & 99.124 & & & & & & \\
15 & .131 & .876 & 100.00 & & & & & \\
\hline
\end{tabular}

(Source: authors' computation)

The following item resulting from the factorial analysis is given by the components' matrix resulting from the extraction according to the principal component analysis. Thus, from the initial data analysed, the retrieval of a number of 5 components has resulted, whose effect is $74.046 \%$ of the total of 15 components analysed. Therefore, there were detained as values the components of the analysis with a variation greater than 1 , and, in our case, the value of 1.150 .

By applying the principal component analysis and through the application of Varimax rotation data method with Keiser normalization (table 5), we can also see that the 5 components initially resulting from the factorial analysis are clearly defined.

Table 5. Rotated component matrix

\begin{tabular}{|l|c|c|c|c|c|}
\hline & \multicolumn{5}{|c|}{ Component } \\
\cline { 2 - 6 } & $\mathbf{1}$ & $\mathbf{2}$ & $\mathbf{3}$ & $\mathbf{4}$ & $\mathbf{5}$ \\
\hline Positive experiences unknown individuals & $\mathbf{. 9 0 8}$ & & & .135 & \\
Negative experiences unknown individuals & $\mathbf{. 8 8 9}$ & .141 & & .116 & \\
General opinions & .687 & .267 & & .298 & .151 \\
Positive experiences friends / acquaintances & .166 & $\mathbf{. 8 6 5}$ & .138 & .158 & \\
Negative experiences friends / acquaintances & .138 & $\mathbf{. 8 6 1}$ & .144 & .210 & \\
Opinions about products or services & .497 & .573 & & & .199 \\
Information sources for product/services & .111 & & $\mathbf{. 9 0 5}$ & .146 & .105 \\
General source of information & & & $\mathbf{. 8 9 9}$ & & .120 \\
Can be used in promotional activities & & .293 & $\mathbf{. 6 0 9}$ & .141 & .159 \\
Companies' pages & .187 & & & $\mathbf{. 8 6 8}$ & .106 \\
Products' / services' pages & .159 & .161 & .267 & $\mathbf{. 8 4 2}$ & .121 \\
Promotional activities & .160 & .398 & .127 & $\mathbf{. 6 3 6}$ &
\end{tabular}


Modelling the Influences of Online Social Networks on Consumers' Buying Behaviour

\begin{tabular}{|l|c|c|c|c|c|}
\hline & \multicolumn{5}{|c|}{ Component } \\
\cline { 2 - 6 } & $\mathbf{1}$ & $\mathbf{2}$ & $\mathbf{3}$ & $\mathbf{4}$ & $\mathbf{5}$ \\
\hline Criticism about products or services & & .146 & .103 & & $\mathbf{. 9 1 0}$ \\
\hline Recommending products / services in general & & & .166 & & $\mathbf{. 9 1 0}$ \\
Recommending products / services by friends & .243 & & .132 & .248 & .365 \\
\hline
\end{tabular}

Extraction Method: Principal Component Analysis.

Rotation Method: Varimax with Kaiser Normalization.

a. Rotation converged in 6 iterations.

(Source: authors' computation)

By analysing the initial components' matrix and by applying Varimax with Kaiser normalization rotation method, five factors (components) were identified to allow the modification of the model, so there is no significant loss of information: Experiences of products and services, expressed as OSN by strangers; Experiences of products and services, expressed through OSN by friends / acquaintances; Information sources from the OSN; Recommendations and critics about products / services through OSN; Advertising conducted through OSN.

By changing and adjusting the model (figure 1) using the 5 factors (components) we continued by validating the links between the extracted components and purchasing behaviour by calculating the connection coefficient and level of statistical significance. The connection coefficient's values between the extracted components and purchasing behaviour exceed the 0.01 threshold, which means that there is a link between the elements analysed and also validate the links between variables. The strongest link is between the Information sources through OSN and the purchasing behaviour (0.465), while the weakest link is the Experience expressed by friends / acquaintances and the purchasing behaviour (0.219).

DOI: $10.24818 / 18423264 / 52.2 .18 .01$ 


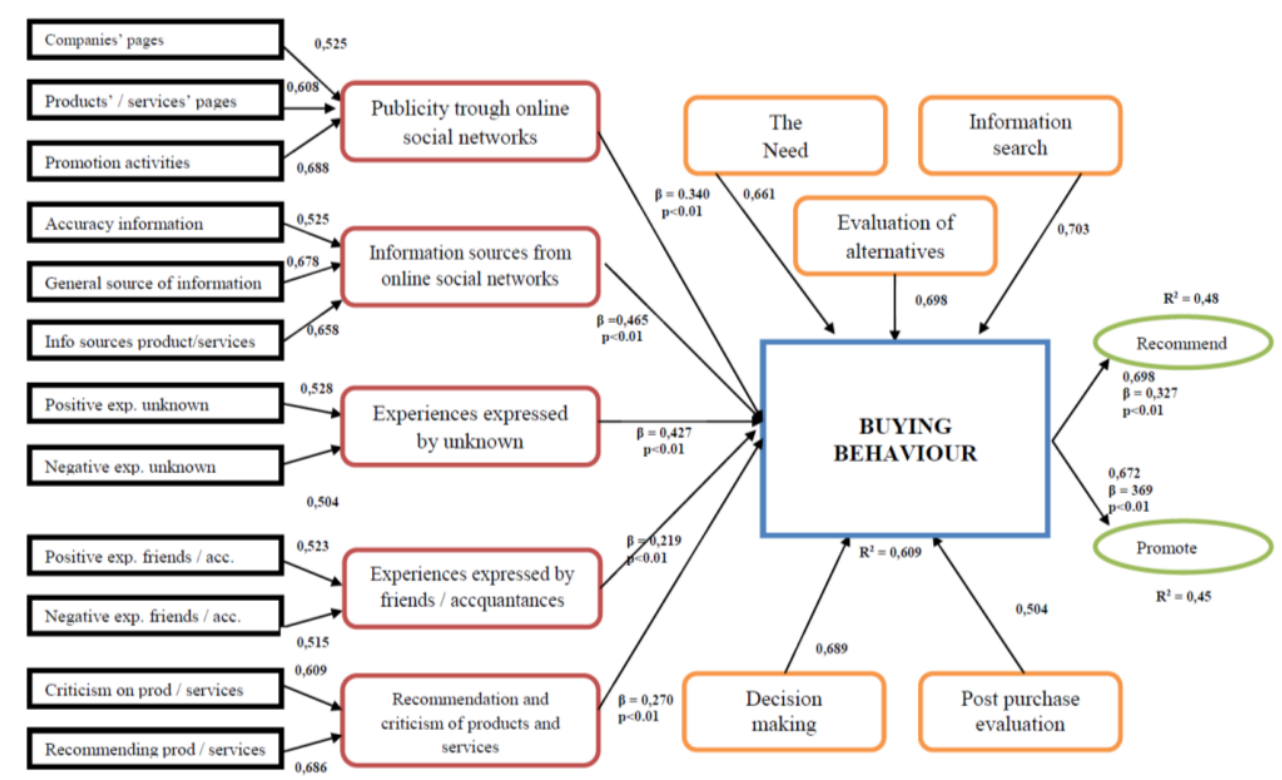

Figure 1: Conceptual model of online influences of online social networks on the purchasing behaviour (I-OSN-CC)

Starting from the analysis of figure 1 and table 6 , we can begin validating the model I-OSN-CC on the basis of the direct effects calculated using the link coefficients $(\beta)$ shows the relationship between components extracted and the purchasing behaviour. Also, these analyses took into account that there must be a level of statistical significance between the investigated data (Sig. or p), which must be less than 0.05 .

Table 6. Validating the links between the extracted Components and the buying behaviour

\begin{tabular}{|l|c|c|c|}
\hline \multicolumn{1}{|c|}{ Link between the variables } & $\begin{array}{c}\text { Coefficient } \\
\text { of link ( })\end{array}$ & $\begin{array}{c}\text { Sig. } \\
\text { level (p) }\end{array}$ & $\begin{array}{c}\text { Validation } \\
\text { of link }\end{array}$ \\
\hline Publicity trough OSN $\rightarrow$ Buying behaviour & 0.340 & $<0.01$ & YES \\
\hline Information sources from OSN $\rightarrow$ Buying beh. & 0.465 & $<0.01$ & YES \\
\hline Exp. Expressed by unknown $\rightarrow$ Buying behaviour & 0.427 & $<0.01$ & YES \\
\hline Exp. Expressed by friends / acq. $\rightarrow$ Buying beh. & 0.219 & $<0.01$ & YES \\
\hline Recommend / criticism to prod/serv. $\rightarrow$ Buying beh. & 0.270 & $<0.01$ & YES \\
\hline
\end{tabular}

(Source: authors' computation)

Analysing the data presented in Table 6.15., it can be seen that the connection coefficient between the components extracted and the purchasing behaviour exceeds the value of 0.01 , which means that there is a link between the elements analysed. The strongest link registered is between the Information sources by OSN 
Modelling the Influences of Online Social Networks on Consumers' Buying Behaviour

and Purchasing behaviour (0.465), while the weakest link is Experience expressed by friends / knowledge and Purchasing behaviour (0.219).

Moreover, the coefficient of determination $\left(R^{2}\right)$ was also calculated, to explain the value of covariance on the total volume of variation and the percentage of total variation which is explained by the independent variables.

After applying linear regression analysis, a coefficient of determination $R^{2}$ $=0.609(60.9 \%)$ was calculated for the purchasing behaviour, which means that Advertising conducted by OSN, Information sources by OSN, Experiences expressed by strangers, Experiences expressed by friends / knowledge and Recommendations / criticisms to products / services by OSN, influence in a proportion of $60.9 \%$ the purchasing behaviour of online social network users.

At the same time, the purchasing behaviour influences in a proportion of $48 \%$ the recommendations and criticism on the one hand and on the other hand it influences the promotion activities in a proportion of $45 \%$. From completing the above statistic data, but also their significance, we get to the conclusion that the proposed conceptual Model of online social networks influences on the purchasing behaviour $(\mathrm{I}-\mathrm{OSN}-\mathrm{CC})$ is validated by the results of the research.

\section{Conclusions, implications and acknowledgements}

By tackling the field of online social networking sites, its usage and the consumer and its buying behaviour we hoped, and succeeded, in identifying how this new communication platform can influence the individuals' behaviour with relation to purchasing products or services. Through this paper we have undertaken a literature review linked to the online social networks, consumer, marketing models on one side, and on the other side we have presented the methodology for a quantitative marketing research (which is part of a larger qualitative and quantitative research) and the creation and validation of a marketing model entitled: Model of online social networks influences on the purchasing behaviour (I-OSN-CC).

The proposed conceptual model involved analysing the influence of a number of observable variables on the latent variables, which in turn have an influence effect on the purchasing behaviour of the individual. The testing and validation activity of the conceptual model proposed involved going through several important stages in the process of marketing modelling: (a) Determining the accuracy of measurements through Cronbach's Alpha coefficient; $(b)$ Correlation analysis between the variables investigated and the purchasing decision making stages; (c) Exploratory factor analysis, followed by the model's adjustment and calculation of connection coefficients and determination of the extracted components and purchasing behaviour.

After completing the above mentioned statistical analysis as well as pointing out their significance as shown in section 4 of this paper, we can clearly state that the proposed conceptual model of online social networks influences on the purchasing behaviour $(I-O S N-C C)$ is validated by research results. 
By developing this research, in addition to the literature review, through the qualitative and quantitative researches, it was intended to make a validated conceptual marketing model that can be a starting point for future studies, its components being used in further studies in this field or modified, adjusted to provide basic components of future research.

From a methodological point of view, the current thesis has a clear, logical structure, based on stages of marketing research supporting the consistency and viability of the study. Developing the proposed and validated marketing model has clearly delimitated a series of formative observable variables, from online social networks, leading to the development of latent variables and strongly influencing the purchasing behaviour of the users, as evidenced by the statistical validation of data.

A crucial element of this article is the managerial implications that it has. Thus, we consider it extremely important that marketers and companies in general are aware of the effect that online social networks have on consumers. At the same time, they should: (1) be aware of the advantages and disadvantages that implementing marketing strategies based on online social platforms brings; (2) understand the kinds of online social networks and their specific features before implementing these strategies; (3) know the general or specific profile of users of online social networks; (4) be able to limit the negative effects caused by wrong decisions or denigrating campaigns of the company / product or services etc. (5) know the familiar elements of online social networks that influence the purchasing behaviour of individuals; (6) know the perception of users on online social networks as a medium for promotion, information, purchase and post purchase behaviour etc.

We have to acknowledge certain limits of our research. One of the most important is that the research conducted has been based on a non-probability sampling method based on the snowball method, which does not allow results to be generalized to the entire population. In addition, we believe that the presence of a more females in the sampling and the lack of people aged under 18, is not a faithful transposition of the statistics of online social network users in Romania. Moreover, the research was a cross study, and the results are valid for a certain period time.

Regarding future activities and research, we consider it necessary to develop further studies in the same direction by applying longitudinal studies with a probabilistic sampling method to follow the time evolution of the phenomenon of online social networks' influences on the purchasing behaviour and to improve the expertise in marketing and purchasing behaviour.

\section{REFERENCES}

[1] Acatrinei, C., Nistor, F.N. (2012), The Romanian Perspective upon the Social Customer and Online Social Networks; Management \& Marketing challanges for the knowledge society, vol. 7 no. 2, pp. $221-236$;

[2] Ajzen, I. (2012), Martin Fishbein's Legacy: The Reasoned Action Approach; Annals of the American Academy of Political and Social Science, 03/2012, vol. 64; 
Modelling the Influences of Online Social Networks on Consumers' Buying Behaviour

[3] Ajzen, I. (2011), The Theory of Planned Behavior: Reactions and

Reflections; Journal of Psychology and Health, vol. 26, no. 9, September, pp. 1113 - 1127;

[4] Ajzen, I. (1985), From Intentions to Actions: A Theory of Planned Behavior, in Kuhl and Beckman (1985), Action-control: From cognition to behavior, Heidelberg, Springer, pp. 11-39;

[5] Alsubagh, H. (2015), The Impact of Social Networks on Consumer Behavior; International Journal of Business and Social Science, vol. 6, no. 1, pp. 209 - 216;

[6] Boyd, D.M., Ellison, N., B. (2007), Social Network Sites: A Definition,

History and Scholarship; Journal of Computer Mediated Communication, vol.13,

(1), http://jcmc.indiana.edu/vol13/issue1/boyd. ellison. html;

[7] Cain, J. (2008), Online Social Networking Issues within Academia and

Pharmacy Education; American Journal of Pharmaceutical Education, 72 (1), art.

10, pp. 1-7;

[8] Cătoiu, I., Teodorescu, N. (2004), Comportamentul consumatorului; Second

Edition, Uranus Publishing, București, 2004;

[9] Cătoiu, I. (2009), Cercetări de marketing-tratat; Uranus Publishing,

Bucuresti;

[10] Ceptureanu, S. I., Ceptureanu, E. G., Orzan, M. C., Marin, I. (2017),

Toward a Romanian NPOs Sustainability Model: Determinants of Sustainability; Journal Sustainability, ISSN 2071-1050, vol. 9, issue 6, pp. 966-992;

[11] Davis, F.D. (1989), Perceived Usefulness, Perceived Ease of Use and User Acceptance of Information Technology; MIS Quaterly, vol. 13, issue 3, pp. 319339 ;

[12] Di Pietro, L., Pantano, E. (2012), An Empirical Investigation of Social Network Influence on Consumer Purchasing Decision: The Case of Facebook, Journal of Direct, Data and Digital Marketing Practice, vol. 14, issue 1, pp. 18 29;

[13] Dumitrescu, L., Orzan G., Fuciu M. (2015), Understanding the Online Consumer Behaviour and the Usage of the Internet as a Business Environment A Marketing Research; Revista Economică vol. 67, issue 3, pp. 63-79;

[14] Eliashberg, J., Lilien, G. (1993), Mathematical Marketing Models: Some

Historical Perspectives and Future Projects, in Handbooks in Operations

Research and Management Science: Marketing, Vol. 5, Elsevier Science Publishers B.V., Amsterdam, pp. 3-23;

[15] Fishbein, M., Ajzen I. (2010), Predicting and Changing Behavior: The Reasoned Action Approach; New York, NY: Psychology Press;

[16] Fuciu M. (2015), Study Regarding the Profile of the Romanian Online

Social Networking Users in Relation to their Buying Behaviour, proceedings of the SELTH 2015 International Scientific Conference of the Romanian-German University of Sibiu, $20-21^{\text {st }}$ of November, Sibiu, Burg Publishing House, pp. 92101 ; 
Iuliana Cetina, Luigi Dumitrescu, Mircea Fuciu, Gheorghe Orzan, Cristina Stoicescu

[17] Fuciu M., Dumitrescu L. (2014), Using Online Social Networking Sites for Doing Business - A Marketing Research; Annales Universitatis Apulensis Series Oeconomica, 16(2), pp. 159 - 170;

[18] Harris, L., Dennis, C. (2011), Engaging Customers on Facebook: Challanges for e-retailers; Journal of Consumer Behavior, vol. 10, pp. 338-346;

[19] Heideman, J., Klier, M., Probst, F. (2012), Online Social Networks: A Survey of a Global Phenomenon; Computer networks journal, vol. 56, pp. 3866 - 3878; [20] Koufaris, M. (2002), Applying the Technology Acceptance Model and the Flow Theory to Online Consumer Behavior; Information System Research, vol. 13, no. 2, pp. 205 - 223;

[21] Kwon, O., Wen, Y. (2010), An Empirical Study of the Factors Affecting Social Network Service Use; Computers in Human Behavior, vol. 26, nr. 4, pp. 254-85, in Romero, C.L., Constantinides, E., Alarcon-del-amo, M.D, Consumer adoption of social networking sites: implications for theory and practice; Journal of Research in Interactive Marketing, vol. 5, no. 2/3, 2011, pp. 170-188;

[22] Lilien, G., Roberts, J. (1993), Explanatory and Predictive Models of Consumer Behavior; Handbooks in Operations Research and Management Science: Marketing, Vol. 5, Elsevier Science Publishers B.V., Amsterdam, pp. 27 82 ;

[23] Orzan, M., Cătoiu, I., Macovei, O. I., Iconaru, C. (2014), Modelling Users' Trust in Online Social Networks; Amfiteatrul Economic, ISSN: 1582-9146, vol.16, No.35, pp.289-302;

[24] Preece, J. and Maloney-Krichmar, D. (2005), Online Communities:

Design, Theory and Practice, available at:

http://jcmc.indiana.edu/vol10/issue4/preece.html;

[25] Ruxanda, Gh., Muraru, A., (2010), FDI and Economic Growth. Evidence from Simoultaneous Equation Models; Romanian Journal of Economic Forecasting, vol. 1 / 2010, pp. 45 - 58;

[26] Solomon, M., Bomossy G., Askegaard, S., Hogg, M.K.(2010), Consumer Behaviour-An European Perspective, 4th. Edition, Prentice Hall Europe, England, Essex, 2010 p. 6;

[27] Venkatesh, V., Davis, F.D. (2000), A Theoretical Extension of the Technology Acceptance Model: Four Longitudinal Field Studies; Management Science, vol. 46, no. 2, pp. $186-204$. 